\title{
Análise bacteriológica de músculo e gônadas de vieira, Nodipecten nodosus (Mollusca: Bivalvia), congelados e irradiados
}

\section{Bacteriological analysis of frozen and irradiated scallops' muscle and gonads Nodipecten nodosus (Mollusca: Bivalvia)}

\section{Ivone Costa SOARES ${ }^{1}$; Eliana de Fátima Marques de MESQUITA ${ }^{1}$; Robson Maia FRANCO ${ }^{1}$; Hélio de Carvalho VITAL ${ }^{2}$; Cynthia Annes RUBIÃO ${ }^{3}$}

\author{
${ }^{1}$ Especialização em Irradiação de Alimentos, Universidade Federal Fluminense, Niterói-RJ, Brasil \\ ${ }^{1}$ Departamento de Tecnologia de Alimentos da Faculdade de Veterinária da Universidade Federal Fluminense, Niterói-RJ, Brasil \\ ${ }^{2}$ Centro Tecnológico do Exército, Rio de Janeiro-RJ, Brasil \\ ${ }^{3}$ Especialização em Bacteriologia, Instituto de Microbiologia Prof. Paulo de Góes da Universidade Federal do Rio de Janeiro, Rio
} de Janeiro-RJ, Brasil

\begin{abstract}
Resumo
No presente trabalho foram analisadas amostras de músculo e gônadas de vieira crus e congelados, oriunda de maricultura de Angra dos Reis, Rio de Janeiro, Brasil. Esta pesquisa teve como finalidade a verificação da eficiência da irradiação, utilizando-se doses de 2kGy e 5kGy. Na Contagem de Bactérias Heterotróficas Aeróbias Mesófilas (CBHAM) observou-se diferença estatisticamente significativa do grupo controle em relação ao grupo irradiado a 5kGy; enquanto que para a Contagem de Bactérias Heterotróficas Aeróbias Psicrotróficas (CBHAP) não se observou nenhuma diferença estatisticamente significativa entre os grupos avaliados. O Número Mais Provável (NMP) de Enterococcus spp. não teve sua presença evidenciada em nenhuma das amostras analisadas. Conclui-se que a irradiação, nesta pesquisa, foi eficiente somente para bactérias mesófilas na dose de 5kGy.
\end{abstract}

Palavras-chave: Músculo e gônadas congelados. Irradiação. Contagem de bactérias.

\begin{abstract}
The present article investigated the effectiveness of irradiation process to conservate frozen raw scallops' muscle and gonads. Samples of this animal were collected from cultivated areas at Angra dos Reis, Rio de Janeiro state, Brazil. The samples were submitted to treatment of 2 and $5 \mathrm{kGy}$ doses. Mesophilic Aerobic Heterotrophic Bacteria Count showed a statistically significant difference from the control group related to the $5 \mathrm{kGy}$ one, while for the Heterotrophic Bacteria Aerobic Psychrotrophic Count were not observed any statistically significant difference among the analysed groups. The Most Probable Number of Enterococcus spp. was not evident in any of the samples. It was concluded that irradiation was effective only for mesophilic bacteria using the $5 \mathrm{kGy}$ dose in this research.
\end{abstract}

Keywords: Frozen scallop's muscle and gonads. Irradiation. Bacteria count.

\section{Introdução}

A espécie Nodipecten nodosus (Linnaeus, 1758) conhecida popularmente como vieira, pertence à família Pectinidae e tem alto valor econômico, sustentando uma importante indústria de extração e cultivo em diversos países ${ }^{1}$.

O consumo de moluscos crus ou parcialmente cozidos está relacionado à presença de agentes etiológicos transmissíveis por alimentos e determinadores de doenças. Segundo a Legislação Nacional - RDC n ${ }^{\circ}$ 12 de 2 de janeiro de 2001, da Agência Nacional de
Vigilância Sanitária, o pescado ou os produtos da pesca devem seguir padrões microbiológicos sanitários referentes aos níveis de coliformes a $45^{\circ} \mathrm{C} / \mathrm{g}$ (colifor-

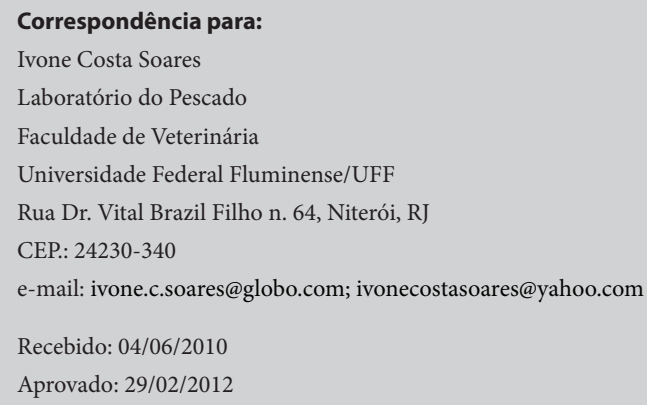


mes de origem fecal/termotolerantes), enumeração de estafilococos coagulase positiva e determinação de Salmonella sp. (presença e ausência). Com relação ao Enterococcus spp. não existe nenhum padrão microbiológico. No entanto, no Anexo II da Legislação, menciona-se que: "Produto ou lote (amostra indicativa ou representativa respectivamente), impróprio para consumo humano por apresentar [...] caso um microrganismo patogênico ou toxina represente perigo severo à saúde do consumidor" ${ }^{2}$.

O objetivo desse trabalho é avaliar a eficiência do processo de irradiação em músculo e gônadas de vieira, congelados, com relação aos parâmetros bacteriológicos.

\section{Material e Método}

As vieiras (Nodipecten nodosus) foram coletadas de cultivos da Baía de Ilha Grande, Angra dos Reis, Rio de Janeiro, e transportadas em caixas com gelo em abundância para o galpão de uma empresa de maricultura da região. Os animais que se apresentavam com as valvas fechadas e com odor e cor próprios à espécie foram selecionados para a pesquisa. Os exemplares foram submetidos à limpeza, pesados e acondicionados em sacos de polietileno, e posteriormente foram lacrados e congelados, em condições de assepsia. Para a presente pesquisa, foram utilizadas as seguintes partes do animal: músculo adutor e gônadas.

Das 30 amostras transportadas em caixas de poliestireno expandido, 20 foram irradiadas no Laboratório da Divisão de Defesa Química, Biológica e Nuclear do Centro Tecnológico do Exército/CTEx, utilizando-se a fonte de Césio 137. Dez amostras foram submetidas a dose de $2 \mathrm{kGy}$ e outras 10 a dose de $5 \mathrm{kGy}$. As 10 amostras controle (não irradiadas) foram mantidas em freezer.

As amostras irradiadas e as não irradiadas (controle) foram transportadas para o Laboratório de Controle Microbiológico de Produtos de Origem Animal,
Departamento de Tecnologia de Alimentos, Faculdade de Veterinária, Universidade Federal Fluminense. Foram realizadas as seguintes análises bacteriológicas: Contagem de Bactérias Heterotróficas Aeróbias Mesófilas (CBHAM), Contagem de Bactérias Heterotróficas Aeróbias Psicrotróficas (CBHAP) e Enumeração de Enterococcus spp., tanto nas amostras irradiadas como nas amostras controle. O preparo das amostras foi baseado em Midura e Bryant ${ }^{3}$; as contagens de BHAM, segundo Morton ${ }^{4}$ e Swanson, Petran e Han$\operatorname{lin}^{5}$ e BHAP, segundo Cousin, Jay e Vasavada ${ }^{6}$ foram realizadas por técnica de miniaturização, segundo Franco e Leite; ; e o Número Mais Provável (NMP) de Enterococcus spp. segundo $\mathrm{Merck}^{8}$ modificado por Franco e Leite ${ }^{7}$.

A descrição estatística das variáveis utilizou gráficos de caixa e hastes ("box plot") e os parâmetros média, desvio padrão, mediana e intervalo semiquartílico. A normalidade dos dados foi verificada por meio do teste de Shapiro-Wilk. A comparação conjunta dos três grupos de dados foi realizada pelo teste de KruskalWallis e as comparações múltiplas decorrentes entre dois grupos de dados foram feitas utilizando-se o teste de Mann-Whitney. As decisões estatísticas utilizaram o nível de significância $\alpha=0,05$.

\section{Resultados}

Em relação à Contagem de Bactérias Heterotróficas Aeróbias Mesófilas (CBHAM) não foram observadas diferenças estatísticas significativas entre as amostras não irradiadas (controle) e as amostras irradiadas a $2 \mathrm{kGy}$; porém, foram observadas diferenças estatísticas significativas entre as amostras controle e as amostras irradiadas a 5kGy. Quanto à Contagem de Bactérias Heterotróficas Aeróbias Psicrotróficas (CBHAP) não foram observadas diferenças estatísticas significativas entre as amostras controle e as amostras irradiadas a 2kGy e a 5kGy. O resultado do Número Mais Provável (NMP) para Enterococcus spp. foi negativo. 
Os diagramas de caixa e hastes ("box plots") apresentam a distribuição da quantidade de UFC presente nos três grupos experimentais para CBHAM (Figura 1).

Observa-se no Grupo irradiado a 5kGy uma amostra com valor muito alto, configurando um valor desgarrado ("outlier").

O teste de Kruskal-Wallis, ao nível de significância de 0,05 , indicou evidência de diferença estatística significativa $(\mathrm{p}<0,05)$ nos grupos $(\mathrm{H}=7,493$; g.l. $=2$; valor-p $=0,024)$.

Assim, o teste de Mann-Whitney evidenciou diferença estatisticamente significativa $(\mathrm{p}<0,05)$ quanto à presença de unidades formadoras de colônias entre o grupo controle e o grupo irradiado a $5 \mathrm{kGy}$, com valores menos elevados para o grupo irradiado a 5kGy.

Os diagramas de caixa e hastes ("box plots") apresentaram a distribuição da quantidade de UFC presente nos três grupos experimentais para CBHAP (Figura 2).
O teste de Kruskal-Wallis, ao nível de significância de 0,05 , indicou inexistência de diferença estatística significativa $(\mathrm{p}>0,05)$ entre os grupos $(\mathrm{H}=3,006$; g.l. $=2$; valor $-\mathrm{p}=0,222$ )

O resultado do NMP das amostras analisadas, tanto as controle como as irradiadas a $2 \mathrm{kGy}$ e $5 \mathrm{kG}$, foi negativo para Enterococcus spp., portanto, não foi constatada a presença desse microrganismo em nenhuma das amostras avaliadas.

\section{Discussão}

A contaminação do ambiente pode representar uma grande ameaça a malacocultura, devido à possibilidade de contaminação da carne dos moluscos bivalves, animais filtradores, podendo apresentar uma elevada concentração de patógenos e gerando um perigo potencial do ponto de vista de Saúde Pública. A maioria dos moluscos é consumida crua ou após ligeiro cozi-

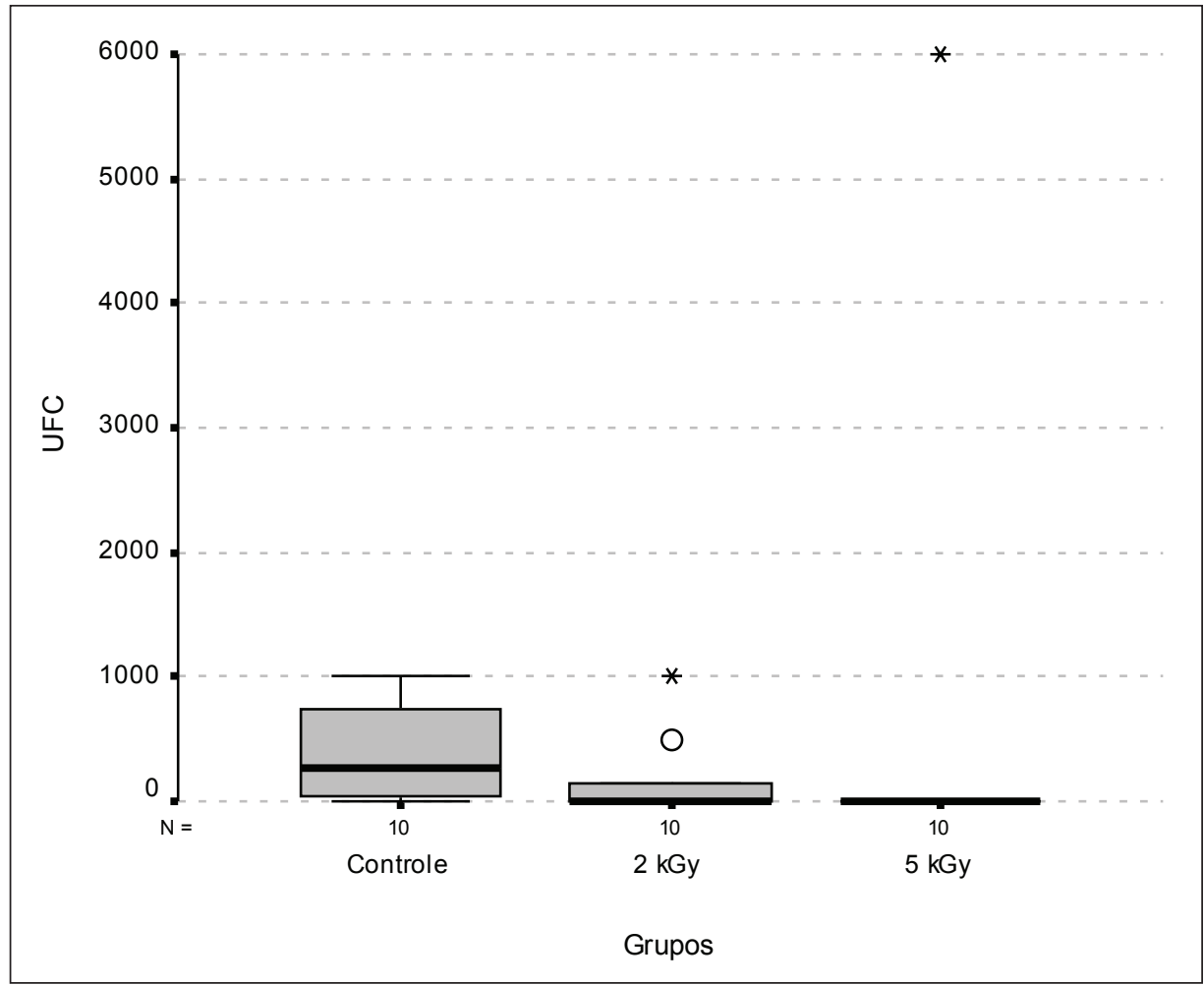

Figura 1- Diagrama de caixa e hastes expressando os resultados médios em UFC da CBHAM. O limite superior da caixa indica o percentil de $75 \%$ dos dados e o inferior 25\%. Asteriscos representam os resultados que fugiram ao padrão de normalidade na análise dos mesmos 


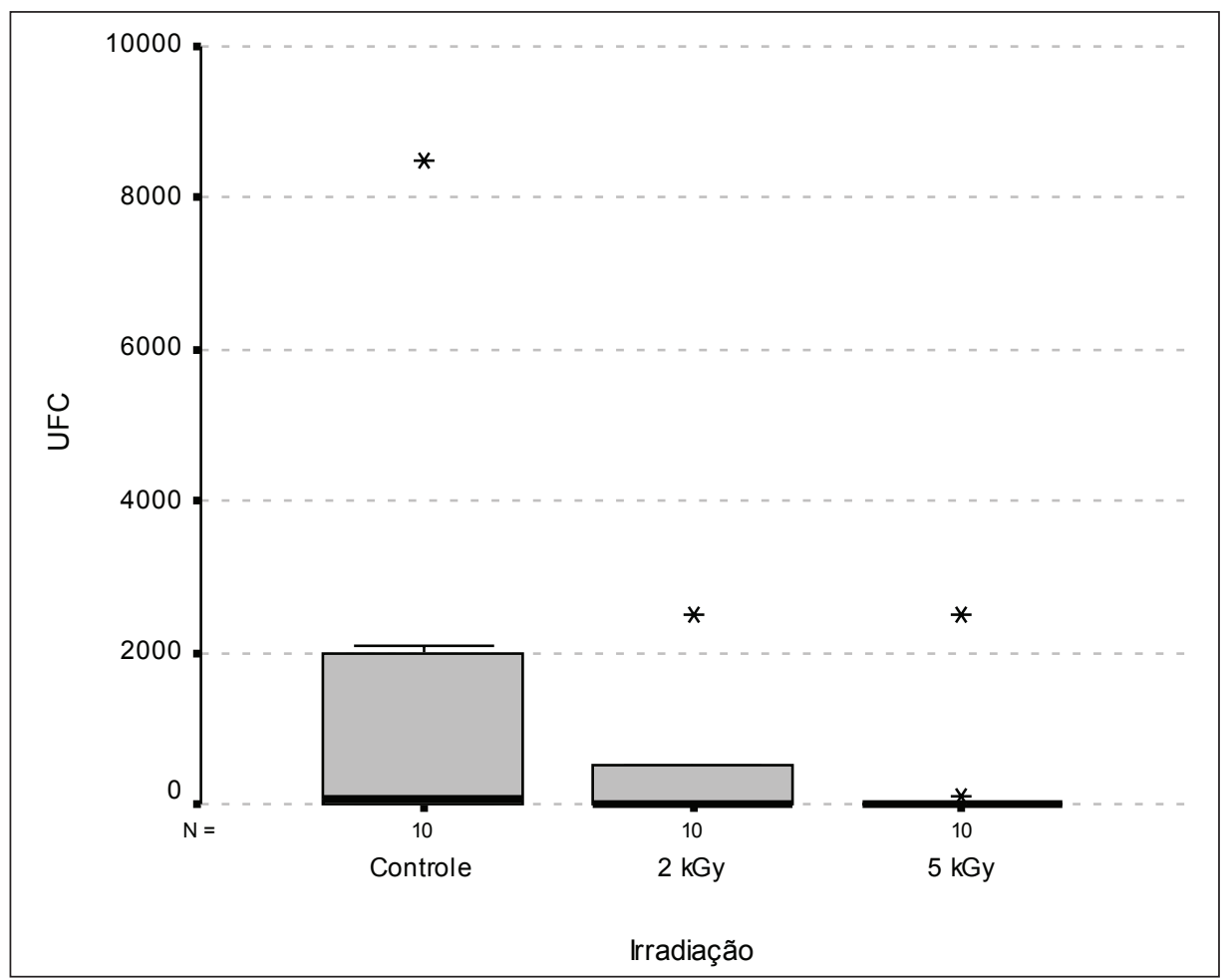

Figura 2 - Diagrama de caixa e hastes expressando os resultados médios em UFC da CBHAP. O limite superior da caixa indica o percentil de $75 \%$ dos dados e o inferior 25\%. Asteriscos representam os resultados que fugiram ao padrão de normalidade na análise dos mesmos

mento. Com isso, torna-se um alimento de alto risco para a saúde do consumidor (HUSS) ${ }^{9}$.

Valente $^{10}$, ao estudar mexilhões congelados e irradiados na dose de $2 \mathrm{kGy}$, observou que a irradiação foi eficaz na redução da microbiota avaliada. Este autor observou eficácia maior sobre as CBHAP, diferenciando-se de nossa pesquisa, em que não foram observadas diferenças estatísticas significativas tanto nas CBHAM como nas CBHAP, nas amostras irradiadas a $2 \mathrm{kGy}$. Da mesma forma, não foram observadas diferenças significativas para CBHAP nas amostras irradiadas na dose de $5 \mathrm{kGy}$.

Dias $^{11}$, ao pesquisar ostras irradiadas na dose de $2 \mathrm{kGy}$ e congeladas, encontrou como resultado valores numéricos nas CBHAM que demonstram a eficácia da irradiação em suas amostras, diferenciando-se de nossa pesquisa, em que os resultados encontrados, não foram observadas diferenças estatisticamente sig- nificativas entre as amostras controle e as amostras irradiadas a $2 \mathrm{kGy}$.

Marins $^{12}$, ao irradiar carne de rã refrigerada e congelada, observou que em relação à CBHAM não houve diferença significativa entre o controle e as amostras irradiadas a $2 \mathrm{kGy}$, mas ocorreu diferença estatística quando comparadas com as amostras irradiadas na dose de $5 \mathrm{kGy}$ e na de $7 \mathrm{kGy}$. Em nossa pesquisa somente diferenças estatísticas entre as amostras controle e as irradiadas na dose de 5kGy foram evidenciadas. Em relação à CBHAP, Marins ${ }^{12}$ observou que o controle, quando comparado com as amostras irradiadas a $2 \mathrm{kGy}$ e a $5 \mathrm{kGy}$, não apresentou diferença significativa ao passo que, comparando-as com as amostras irradiadas a 7kGy, houve confirmação da existência de diferença significativa. Esses resultados foram semelhantes aos encontrados em nossa pesquisa onde não foram observados resultados estatísticos 
significativos em relação à CBHAP, comparando as amostras controle com as irradiadas a $2 \mathrm{kGy}$ e a $5 \mathrm{kGy}$.

Calixto et al. ${ }^{13}$, pesquisando anéis de lula congelados e irradiados, observaram que a dose de 1,5kGy mostrou-se mais apropriada para promover a redução da carga bacteriana dos microrganismos mesófilos, resultado diferente de nossa pesquisa, em que não foram observadas diferenças estaticamente significativas entre as amostras não irradiadas e as irradiadas a $2 \mathrm{kGy}$. Os mesmos autores ${ }^{13}$ observaram que a dose de $3 \mathrm{kGy}$ mostrou-se mais eficiente para microrganismos psicrotróficos, ao passo que em nossa pesquisa não foram evidenciadas diferenças estatísticas significativas entre as amostras não irradiadas e as irradiadas em 2 e 5kGy.

Para Santos et al. ${ }^{14}$, a irradiação foi satisfatória nas doses de 3 e 5kGy para eliminação de bactérias heterotróficas aeróbias psicrotróficas em carne de siri congelada. Na nossa pesquisa não foram evidenciadas diferenças estatísticas significativas entre as amostras não irradiadas e as irradiadas a 2 e 5kGy.

Para Valente ${ }^{15}$, a irradiação apresentou eficácia sobre a microbiota estudada, sendo mais efetiva sobre Escherichia coli do que sobre Enterococcus spp. Entretanto, no presente trabalho, o resultado da enumeração de Enterococcus spp. das amostras analisadas, tanto as controle quanto as irradiadas a $2 \mathrm{kGy}$ e $5 \mathrm{kGy}$, foi negativo.

\section{Referências}

1. RUPP, G. S.; BEM, M. M. Cultivo de vieiras. In: POLI, C. R.; POLI, A. T. B.; ANDREATTA, E.; BELTRAME, E. Aquicultura: experiências brasileiras. Florianópolis: Multitarefa Editora Ltda., 2004. Cap. 12, p. 289-308.

2. BRASIL. Ministério da Saúde. Resolucão - RDC número 12, de 2 de janeiro de 2001. Brasília DF.: Ministério da Saúde, Agência Nacional de Vigilância Sanitária, 2001.

3. MIDURA, T. F.; BRYANT, R. G. Sampling plans, sample collection, shipment and preparation for analysis. In: DOWNES, F. P.; ITO, K. Compendium of methods for microbiological examination of foods. 4. ed. Washington, D.C.: APHA, 2001. Cap. 2, p. 13-23.

4. MORTON, R. D. Aerobic plate count. In: DOWNES, F. P.; ITO, K. Compendium of methods for microbiological examination of foods. 4. ed. Washington, D.C.: APHA, 2001. Cap. 7, p. 63-67.

5. SWANSON, K. M. J.; PETRAN, R. L.; HANLIN, J. H. Culture

\section{Conclusão}

Em relação à Contagem de Bactérias Heterotróficas Aeróbias Mesófilas (CBHAM), não foram observadas diferenças estatísticas significativas entre as amostras não irradiadas (controle) e as irradiadas a $2 \mathrm{kGy}$; entretanto foram observadas diferenças estatísticas significativas entre as amostras não irradiadas (controle) e as irradiadas a $5 \mathrm{kGy}$.

Não foram evidenciadas diferenças estatísticas significativas entre as amostras não irradiadas (controle) e as irradiadas a $2 \mathrm{kGy}$ e a $5 \mathrm{kGy}$ em relação à Contagem de Bactérias Heterotróficas Aeróbias Psicrotróficas (CBHAP).

Não foi encontrada presença de Enterococcus spp. em nenhuma das amostras pesquisadas, tanto nas amostras não irradiadas (controle) como nas irradiadas a $2 k G y$ e $5 k G y$.

Conclui-se que o processo de irradiação, nas amostras analisadas, foi eficaz apenas na dose de 5kGy em relação à Contagem de Bactérias Heterotróficas Aeróbias Mesófilas (CBHAM).

Devido à baixa contagem encontrada e a ausência de Enterococcus spp., evidenciou-se que os procedimentos de manipulação e armazenagem das amostras avaliadas foram extremamente criteriosos, evitando possíveis contaminações.

methods for enumeration of microorganisms. In: DOWNES, F. P.; ITO, K. Compendium of methods for microbiological examination foods. 4. ed. Washington, D.C.: APHA, 2001. Cap. 6, p. 53-62.

6. COUSIN, M. A.; JAY, J. M.; VASAVADA, P. C. Psychrotrophic microorganisms. In: DOWNES, F.; ITO, K. Compendium of methods for microbiological examination of foods. 4. ed. Washington, D.C.: APHA, 2001. Cap. 13, p. 159-165.

7. FRANCO, R. M.; LEITE, A. M. O. Enumeração e identificação de Enterococcus spp. e cepas de Escherichia coli patogênicas em coxas de frango e estudo da atividade antimicrobiana das cepas isoladas. In: SEMINÁRIO DE INICIAÇÃO CIENTIFICA E PREMMIO UFF VASCONCELLOS TORRES DE CIÊNCIA E TECNOLOGIA, 15., 2005, Niterói, RJ. Anais... Niterói: Pró-Reitoria de Pós-Graduação e Pesquisa/ PROPPi, 2005.

8. MERCK. Microbiology manual cultural media. Dormstadt, Germany: MERCK, 1996. 405 p. 
9. HUSS, H. H. Garantia da qualidade dos produtos da pesca. Roma: FAO, 1997. 182 p. (Documentos Técnicos das Pescas. n. 334).

10. VALENTE, A. M. Verificação da eficácia da radiação gama em mexilhões [Perna perna (LINNAEUS, 1758)], através da contagem de bactérias heterotróficas aeróbias mesófilas e bactérias heterotróficas aeróbias psicrotróficas. 2002. $40 \mathrm{f}$. Monografia (Especialização em Irradiação de Alimentos) Faculdade de Veterinária, Universidade Federal Fluminense, Fluminense, 2002.

11.DIAS, J. F. B. Redução da carga bacteriana da ostra-demangue (Crassostrea rhizophorae) in natura, resfriada e congelada, através da radiação gama. 2002. 89 f. Monografia (Especialização em Irradiação de Alimentos) - Faculdade de Veterinária, Universidade Federal Fluminense, Fluminense, 2002.

12. MARINS, L. A. Utilização da radiação gama na conservação da carne de rã - Touro Americana (Rana catesbeiana). 2003 $82 \mathrm{f}$. Monografia (Especialização em Irradiação de Alimentos)
- Faculdade de Veterinária, Universidade Federal Fluminense, Fluminense, 2003.

13. CALIXTO, F. A. A.; FRANCO, R. M.; MESQUITA, E. F. M.; VITAL, H. C.; MURAYAMA, E. Avaliação bacteriológica de anéis de lula, Dorytheutis plei (Blainville, 1823) (Mollusca: Cephalopoda), congelados e irradiados. Revista Portuguesa de Ciências Veterinárias, v. 104, n. 569/572, p. 71-75, 2009.

14.SANTOS, E. B.; MANTILLA, S. P. S.; SILVA, R. A.; CANTO, A. C. V. C. S.; NUNES, E. S. C. L.; FRANCO, R. M.; JESUS, E. F. O. Radiação gama na redução da microbiota de carne de siri (Callinectes sapidus) pré-cozida, congelada e inspecionada. Boletim do Instituto de Pesca, São Paulo, v. 36, n. 3, p. 175 $183,2010$.

15. VALENTE, A. M. Efeito da irradiação sobre mexilhões [Perna perna (LINNAEUS, 1758)]: Coliformes Termotolerantes e Enterococcus; ação antimicrobiana e análise sensorial das amostras. 2004. 84 f. Dissertação (Mestrado em Medicina Veterinária) - Faculdade de Veterinária, Universidade Federal Fluminense, Niterói. 2004. 